\title{
Modeling Equity Compensation under Accounting Contingencies
}

\author{
John Bizjak $^{1}$, Swaminathan Kalpathy ${ }^{1} \&$ Rex Thompson ${ }^{2}$ \\ ${ }^{1}$ Texas Christian University, USA \\ ${ }^{2}$ Southern Methodist University, USA \\ Correspondence: Rex Thompson, Southern Methodist University, USA. E-mail: rex@ smu.edu
}

Received: December 8, 2015

Accepted: January 23, 2016

Online Published: January 26, 2016

doi:10.5430/afr.v5n1p164

URL: http://dx.doi.org/10.5430/afr.v5n1p164

JEL classification:

G130

G34

G390

L140

We thank the accounting workshop at Southern Methodist University and Dimitris Vrettos for skepticism, comments and encouragement.

\begin{abstract}
Of late, both U.S. and International firms have increased the granting of performance-contingent equity awards to their executive officers. Beyond simple stock options, these awards frequently include accounting-based performance targets. Failure to meet or exceed these targets causes award forfeiture. While now a common component in executive pay, little is known about how to value these instruments. In this paper, we model the expected payoff from an equity award with accounting-based payout conditions. The model incorporates numerous characteristics of awards seen in practice, including the coupling of stock price and accounting targets, multiple accounting targets, sliding payout schedules, and the adoption of both "and" and "or" conditions that trigger payout. We also translate the expected payoff into an approximate present value. Given the growing prevalence of performance-contingent features in executive pay, this exercise is important to academics, board members and shareholders, along with other market participants and regulators.
\end{abstract}

Keywords: Executive compensation, Performance-vesting, Accounting contingencies, P-v awards

\section{Introduction}

Over the last several decades, stock options and restricted stock awards with time vesting have been the primary form of equity-based pay for corporate executives. (Note 1) The motivation behind the use of these instruments is to focus managerial effort on improving the firm's stock price. Recently, however, simple time-vesting of stock awards has come under criticism as rewarding executives for reasons often unrelated to executive effort or abilities. In fact, commentators have referred to traditional time-vested stock and option awards as nothing more than "pay for pulse." (Note 2)

Perhaps because of investor concerns over the structure of incentives provided by time-vested stock and option awards, in recent years there has been a substantial increase in restricted stock and option awards containing performance-based vesting conditions (henceforth $\mathrm{p}-\mathrm{v}$ awards). In addition, there has been significant growth in the use of accounting measures as vesting criteria. In juxtaposition with $\mathrm{p}-\mathrm{v}$ awards that vest based solely on stock price, we use the term a-c award to mean a p-v award containing at least one accounting contingency. Bettis, Bizjak, Coles, and Kalpathy (2015), hereafter BBCK, document that, among the approximately 1,800 largest U.S. firms by market capitalization, the proportion using performance-vesting conditions in equity awards increased significantly from $21 \%$ in 1998 to $68 \%$ in 2012. Moreover, the proportion of equity awards tied to performance-vesting conditions for executives increased from $12 \%$ in 1998 to $41 \%$ by 2012. (Note 3) (Note 4) With regard to the use of accounting-based 
performance measures, in $1998,51 \%$ of $\mathrm{p}-\mathrm{v}$ awards had at least one accounting performance threshold while the rest focused on stock price. By 2012, however, 75\% of p-v awards had at least one accounting performance threshold. The most frequent accounting measures in their data involve some form of earnings, followed by sales.

Since awards involving performance-vesting and the use of accounting targets are now prevalent, understanding the value and incentive effects of these contracts is important to academics, practitioners, and regulators. (Note 5) Yet research examining these issues is just starting. Our purpose is to contribute to this stream. We begin in Section 2 by describing several examples of a-c awards along with a review of related work. Section 3 quantifies the expected payoff for a-c awards and examines a number of performance-vesting alternatives, each motivated with examples from recent corporate proxy statements. There is also a brief digression into present value and subjective valuation of a-c awards. Sections 4 and 5 provide a framework for examining the incentive properties of a-c awards. The question addressed is why firms might choose a-c awards over traditional $\mathrm{p}-\mathrm{v}$ awards tied only to stock price. Section 6 concludes the paper, while Appendix A contains several useful analytic results.

\section{Changing Landscape of Executive Pay}

\subsection{Vesting Characteristics in Executive Compensation}

Consider the compensation contract for Coca-Cola Enterprises Inc. The following is excerpt from the company's proxy statement, dated March 4, 2009:

Performance Share Units. PSUs provide our senior officers the opportunity to receive shares of our stock only if both a performance objective and a continued-service requirement are met... ... The performance objective set by the Committee for the 2008 PSUs is the annual growth rate in our earnings per share ("EPS") for the 2009 fiscal year over 2008 EPS... ... Using 2008 EPS of \$1.32, the minimum, target, and maximum EPS performance goals, and the corresponding award levels set by the Compensation Committee, are:

\begin{tabular}{lll}
\hline $\begin{array}{l}\text { Annual Growth Rate in } \\
\text { EPS FY 2009 vs. FY }\end{array}$ & $\begin{array}{l}2009 \text { EPS } \\
\text { Goals }\end{array}$ & $\begin{array}{l}\text { Percentage of the PSU } \\
\text { Target Award Earned }\end{array}$ \\
\hline Le08 & $\$ 1.35$ & $0 \%$ \\
Minimum-2\% & $\$ 1.35$ & $50 \%$ \\
Target-6\% & $\$ 1.40$ & $100 \%$ \\
Maximum-10\% & $\$ 1.45$ & $200 \%$ \\
\hline
\end{tabular}

[Emphasis added]

There are two primary features. The first is the performance metric; Coca Cola uses earnings per share (EPS). The second feature is the payout schedule. The most common payout schedules, illustrated by Coca Cola, have a minimum hurdle below which no shares are earned. For performance above the minimum, increasing numbers of shares are granted until a maximum level of performance is achieved, capping the number of shares.

While a single performance-vesting condition is perhaps the most common, there are a number of a-c awards with more complex vesting structures. One complication involves multiple criteria, where vesting requires the achievement of several performance goals simultaneously. As an illustration, in 2007 Aldrich Corp granted the following stock award with multiple a-c targets. According to the proxy statement:

The Committee has established specific performance targets for 2008 for each goal listed above that will be appropriately challenging and consistent with achieving the Company's long-term growth and profitability objectives. These objectives are to grow sales and operating income on average 10\% each year and provide a return on equity of $20 \%$ over the long term ... The Committee established financial performance measures and targets for the 2007 to 2009 performance period, including (1) a compound annual growth rate in sales of $10 \%$ and (2) an average return on equity of $20 \%$, consistent with objectives of the Company's strategic plan. [Emphasis added]

In contrast with Aldrich Corp, a-c awards are sometimes granted with multiple targets, but only one target needs to be achieved for vesting. (Note 6) Sotheby's has this discussion in its 2006 proxy statement:

For the Performance Shares granted in 2006, restricted stock awarded will vest three and five years after the grant date only upon the occurrence of either:

A compound increase in shareholder return, including stock price and dividends 
$\boldsymbol{O R}$

\section{A compound cumulative increase in Sotheby's net income}

In designing the Performance Shares program, the Committee relied in part on analyses and recommendations from Cook, a nationally recognized executive compensation consulting firm. The Committee determined that the net income target as an alternative to the stockholder return target was desirable because the Company's stock price might not reflect the Company's actual financial performance at any given point in time. Fluctuations in the Company's stock price can occur due to the art market's cyclical nature and the cyclical nature of the economy and stock market in general. [Emphasis added]

These examples show the level of complexity required to encompass current practice.

\subsection{Related Research}

To date, the bulk of analytic research examining the payoffs, incentive implications and valuation of equity awards with $\mathrm{p}-\mathrm{v}$ provisions has focused on a single type of award - a stock option that only vests if a target stock price is achieved. Kuang and Suijs (2006) examine the incentive effects for this type of award and show that a vesting provision based on stock price attached to stock options can increase managerial effort as long as the vesting threshold is not too demanding. Johnson and Tian (2000A and B) compare the value and incentive aspects of several different types of stock option awards but none containing accounting contingencies. (Note 7)

The void is between traditional stock options and a-c awards is beginning to draw attention, however. Holden and Kim (2014) examine a stock grant with a single accounting vesting condition and provide a model to value this type of instrument. In what follows, we include this special case within a structure that allows us to consider a wide range of additional complexities found in existing contracts. (Note 8)

Along the empirical domain of research, a number of studies have begun collecting facts about the use of $\mathrm{p}-\mathrm{V}$ provisions. In addition to BBCK, Murphy (2013) discusses how changes in disclosure requirements, tax policies, accounting rules, legislation, and the general political climate have affected CEO pay provisions. He notes that FASB $123 \mathrm{r}$, an accounting rule change, has influenced the shift away from stock options into a-c awards. Murphy also suggests that the growing influence of proxy advisors like ISS (2016) has been an impetus for the increase in both p-c generally and a-c awards specifically. In terms of the effects of a-c awards on manager behavior, a recent empirical investigation by Bizjak, Hayes and Kalpathy (2015) suggests that the use of accounting-based compensation metrics is associated with more earnings management. Kim and Yang (2014) find an empirical connection between performance management and the existence of annual incentive targets. Park and Vrettos (2015) investigate the connection between the use of relative performance evaluations and the risk profiles of executives' investment portfolios.

All of this recent research, not surprisingly, supports the view that complex performance-vesting affects management decision-making. The goal of the current paper is to build some structure around the payoff and valuation properties of a class of vesting conditions, so as to help complete the picture of what is gained and what is lost when a-c awards are added to executive pay. If a-c awards influence behavior in a positive direction, what is the cost to the firm of adding them? How is a tradeoff between a-c conditions and the number of awards determined so as to achieve a win-win for the firm and its executives? Which types of firms should benefit most from adding a-c provisions? We hope the structure we develop helps inform the debate surrounding these kinds of questions.

\section{The Expected Payoff and Approximate Valuation of an Equity Award with Performance-Vesting Conditions based on Accounting Criteria}

Our analysis directs primary attention to the relationships between vesting provisions and the expected terminal value or payoff of the award. We also calculate what we refer to as an approximate present value. In contexts where simple Black-Scholes valuation would be appropriate, our approximate present value equals Black-Scholes. (Note 9)

Section 3.1 begins the analysis by examining a-c awards comprised of a stock option as the back-end instrument if and only if thresholds in stock price and a single accounting performance metric are achieved simultaneously. The general structure underlying this award provides a good foundation for the rest of the cases we examine.

Because the most popular accounting vesting criteria reported by BBCK involve earnings targets, for ease of exposition we call the accounting performance metric "earnings." Section 3.2 considers the special case of stock grants, rather than options, as the back-end instrument, which is similar to the contract analyzed by Holden and Kim (2014). In section 3.3, the basic equations are extended to consider payouts that vary over a range of performance levels rather than a single payout with a specific threshold target. Section 3.4 analyzes the case of stock grants awarded as a function 
of two accounting criteria simultaneously (e.g. earnings and sales). Section 3.5 considers the case of an either/or condition where grants are awarded if either of two performance objectives are achieved. A brief discussion of subjective valuation for risk-averse managers is contained in 3.6.

Before turning attention to the analytics, we emphasize a central point of the exercise: successful analysis of a-c awards, their payoff distributions, approximate and subjective valuations, and potential incentive effects require a deep understanding of the joint distribution of stock price and the accounting information on which contingencies are written. To start the ball rolling, we entertain a joint lognormal distribution between stock price and transformations of accounting information, but it is unlikely and not intended that ours will be the last word on this subject. While joint log-normality is a limitation of our paradigm, we anticipate that future research, refining the distributional assumptions, will support the central thrust of intuition that we develop.

To simplify the analysis, we assume that threshold dates, vesting dates and contract expiration dates are all at the same time, T; a condition consistent with the preponderance of these types of awards. Having threshold trigger dates that differ from one another and from the expiration date affects the joint densities and, ultimately, the expected payoff, but the structure of the expected payoff is unchanged.

Throughout the paper we adopt the following notation and augment it as necessary:

$\mathrm{S}_{\mathrm{T}}=$ the stock price at time $\mathrm{T}$

$\mathrm{e}_{\mathrm{T}}=$ the cumulative flow of earnings from 0 to $\mathrm{T}$

$\mathrm{g}(\mathrm{e})$ is the unconditional distribution of $\mathrm{e}_{\mathrm{T}}$

$\mathrm{f}(\mathrm{S})$ is the unconditional distribution of $\mathrm{S}_{\mathrm{T}}$

$\mathrm{g}(\mathrm{e} \mid \mathrm{S})$ is the conditional distribution of $\mathrm{e}_{\mathrm{T}}$ for a given realization of $\mathrm{S}_{\mathrm{T}}$

$\mathrm{f}(\mathrm{S} \mid \mathrm{e})$ is the conditional distribution of $\mathrm{S}_{\mathrm{T}}$ for a given realization of $e_{\mathrm{T}}$

$\mathrm{H}=$ the contract threshold in earnings

$\Delta=$ the contract threshold in stock price

$\mathrm{X}=$ Payoff floor in $\mathrm{S}$ (exercise price)

\subsection{The Expected Payoff from An Option When Vesting is A Function of Stock Price and Earnings}

Our goal in this section is to evaluate the payoff from a contract that pays $\mathrm{S}_{\mathrm{T}}-\mathrm{X}$, iff $e_{T}>\mathrm{H}$ and $\mathrm{S}_{\mathrm{T}}>\Delta$. An a-c award with a stock grant as the backend instrument has $\mathrm{X}=0$. We use the term "stock-based" to describe a contract with no performance metric other than stock price.

Regardless of how $\mathrm{S}_{\mathrm{T}}$ and $e_{T}$ are jointly distributed, the expected contract payoff can either be written as

$$
\bar{P}=\int_{H}^{\infty} \int_{\Delta}^{\infty}\left(S_{T}-X\right) f(S \mid e) g(e) d S d e
$$

or

$$
\bar{P}=\int_{\Delta}^{\infty} \int_{H}^{\infty}\left(S_{T}-X\right) g(e \mid S) f(S) d e d S
$$

Another way to write these expectations is to recognize that the inner integrals are partial expectations of $\mathrm{S}_{\mathrm{T}}-\mathrm{X}$. (Note 10) In equation (1a), the inner integral is the partial expectation of $S_{\mathrm{T}}-X$ for a given realization of earnings and the condition that $\mathrm{S}_{\mathrm{T}}>\Delta$. In equation (1b) the inner integral is the partial expectation of $\mathrm{S}_{\mathrm{T}}-\mathrm{X}$ for a given realization of $\mathrm{S}_{\mathrm{T}}$ and the condition that $e_{T}>\mathrm{H}$. Thus we could write

$$
\bar{P}=\int_{H}^{\infty} E\left(S_{T}-X \mid e_{T}, S_{T}>\Delta\right) \cdot \operatorname{Prob}\left(S_{T}>\Delta \mid e_{T}\right) g(e) d e
$$

or

$$
\begin{aligned}
& \quad \bar{P}=\int_{\Delta}^{\infty} E\left(S_{T}-X \mid S_{T}, e_{T}>H\right) \cdot \operatorname{Prob}\left(e_{T}>H \mid S_{T}\right) f(S) d S \\
& =\int_{\Delta}^{\infty}\left(S_{T}-X\right) \cdot \operatorname{Prob}\left(e_{T}>H \mid S_{T}\right) f(S) d S
\end{aligned}
$$

The distributions driving the threshold conditions are conditional distributions given the realizations of $e_{T}$ or $\mathrm{S}_{\mathrm{T}}$ respectively.

In (2b), the partial expectation inside the integral is $\mathrm{S}_{\mathrm{T}}$-X times the conditional probability that $e_{T}>\mathrm{H}$ given $\mathrm{S}_{\mathrm{T}}$. This latter probability could be interpreted as the "haircut", for a given $\mathrm{S}_{\mathrm{T}}$, created by imposing the additional threshold that $e_{T}$ exceeds $\mathrm{H}$. Since each of these conditional probabilities is less than (or at most equal to) unity, the natural interpretation of the entire expression in (2b) is that it describes a stock-based option having payoff $\mathrm{S}_{\mathrm{T}}-\mathrm{X}$ given $\mathrm{S}_{\mathrm{T}}>\Delta$ 
times an overall haircut imposed by adding a threshold in earnings, $e_{T}$. As long as earnings and stock price are co-dependent, however, it is not possible to move the conditional probability out of the integral and attempt to interpret the unconditional probability that $e_{T}$ fails to achieve its threshold as the implicit overall haircut applied to stock-based option that omits the earnings contingency. The extent of the overall haircut is dependent on the co-movement in stock price and earnings in addition to the unconditional probability that earnings fails to achieve its threshold. With positive correlation between earnings and stock price, both the conditional expectation and the conditional probability increase in $S_{\mathrm{T}}$ and are higher on average when $S_{\mathrm{T}}>\Delta$ than they are unconditionally.

Perhaps the central looming question is how a compensation committee and manager should establish the value-maximizing number of stock awards, and the number and size of performance criteria imbedded therein. What are the gains from trade among these features? A first step is to visualize the comparative statics governing the expected payoff. To this end, we evaluate equations (1) and (2) by imposing distributional assumptions on $\mathrm{S}_{\mathrm{T}}$ and $\mathrm{e}_{\mathrm{T}}$.

Much of the option pricing literature revolves around the assumption that future stock prices are lognormally distributed. What distributional assumptions to make about accounting measures and how they connect to stock price is a less-researched area. We will assume that there exist monotone transformations of accounting measures that are jointly lognormally distributed with stock price (Note 11). One drawback to the lognormal assumption for earnings without a transformation is that it does not allow for negative reported earnings. (Note 12) But companies that deploy an earnings contingency may self-select so that negative earnings is a slim possibility. That the upper tail of the earnings distribution is approximately lognormal might be reasonable. In any event, we will use the notation $e$ to represent a suitable transformation of earnings and $\mathrm{H}$ to represent an equivalent transformation of the threshold.

To incorporate lognormality, let

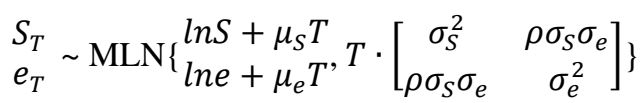

and define the projection equation of log stock price on log earnings as

$$
\begin{gathered}
\ln \left(\frac{\mathrm{S}_{\mathrm{T}}}{\mathrm{S}}\right)=E\left[\ln \left(\frac{\mathrm{S}_{\mathrm{T}}}{\mathrm{S}}\right) \mid e_{T}\right]+\varepsilon_{T}=z_{T}+\varepsilon_{T} \\
z_{T} \equiv E\left[\ln \left(\frac{\mathrm{S}_{\mathrm{T}}}{\mathrm{S}}\right) \mid e_{T}\right]=\mu_{S} T+\frac{\rho \sigma_{S}}{\sigma_{e}}\left[\ln \left(e_{T} \mid e\right)-\mu_{e} T\right] \\
E\left(S_{T} \mid e_{T}\right)=S \cdot \exp ^{\mathrm{z}_{\mathrm{T}}+\frac{\left(1-\rho^{2}\right)}{2} \sigma_{S}^{2} T}=S \cdot \exp ^{\left(\mu_{S} T-\frac{\rho \sigma_{S}}{\sigma_{e}}\left(\ln (e)+\mu_{e} T\right)\right)+\frac{1-\rho^{2}}{2} \sigma_{S}^{2} T} \cdot e_{T}^{\frac{\rho \sigma_{S}}{\sigma_{e}}} \\
\varepsilon_{T} \sim L N\left(0, \sigma_{\varepsilon}^{2} T\right), \text { where } \sigma_{\varepsilon}^{2}=\left(1-\rho^{2}\right) \sigma_{S}^{2}
\end{gathered}
$$

In (3), $\mathrm{z}_{\mathrm{T}}$ is the projection of the change in log stock price on the change in log earnings, $\varepsilon_{T}$ is the projection error, and parameters refer to the parameters of the log values. Price and earnings without subscripts denote the present levels. (Note 13) The parameterization in (3) begs the question of

exactly from where the parameters come. We explore this question in Section 4, but, they should be recoverable from historical data, within the limits of statistical variation.

With lognormally distributed random variables, partial expectations have a compact form. Theorems 1 and 2 in Appendix A extend the standard formula for partial expectations in the univariate case to partial expectations of one lognormal random variable conditional on a second lognormal random variable exceeding a threshold. Rearranging (2a),

$$
\bar{P}=\int_{H}^{\infty}\left[E\left(S_{T} \mid e_{T}, S_{T}>\Delta\right) \cdot \operatorname{Prob}\left(S_{T}>\Delta \mid e_{T}\right)-\operatorname{XProb}\left(S_{T}>\Delta \mid e_{T}\right)\right] g(e) d e
$$

Utilizing Theorems 1 and 2 allows the partial expectation inside the integral to be rewritten as $E\left(S_{T} \mid e_{T}\right) N\left(d_{1}\right)$ and thus

$$
\bar{P}=\int_{H}^{\infty} S \cdot \exp ^{\mathrm{Z}_{\mathrm{T}}+\frac{\left(1-\rho^{2}\right)}{2} \sigma_{S}^{2} T} \cdot\left\{\mathrm{N}\left(\mathrm{d}_{1}\right)\right\}-X \cdot\left\{\mathrm{N}\left(\mathrm{d}_{2}\right)\right\} g(e) d e
$$

where $d_{1}=\frac{\ln \left(\frac{\mathrm{S}}{\Delta}\right)+\mathrm{Z}_{\mathrm{T}}+\sigma_{\varepsilon}^{2} T}{\sigma_{\varepsilon} \sqrt{\mathrm{T}}}, d_{2}=\mathrm{d}_{1}-\sigma_{\varepsilon} \sqrt{T}$ and $\mathrm{N}(\mathrm{q})$ is the cumulative normal to $\mathrm{q}$.

In deriving $d_{1}$ we utilize the fact that, for a given $e_{T}, S_{T}>\Delta$ equals $\varepsilon_{T}>\Delta-Z_{T}$ and that $S_{T} \mid e_{T}$ and $\varepsilon_{T}$ are perfectly correlated. Another approach, leading to the same solution is to let $Y=S_{T} \mid s_{T}$ and $X=S_{T}$ in the theorems. 
When $\mathrm{H}=0$, (4) can be connected to the literature on simple options because no threshold in earnings is present. With $\mathrm{H}=0$, the order of integration is easily reversed in (2a) and, working with (2b), we have

$$
\begin{gathered}
\bar{P}=\int_{\Delta}^{\infty}\left(S_{T}-X\right) \cdot f(S) d S \\
\bar{P}=\left[E\left(S_{T} \mid S_{T}>\Delta\right)-X\right] \operatorname{prob}\left(S_{T}>\Delta\right) \\
\bar{P}=\left\{\mathrm{S} \cdot \exp \left(\mu_{S} \mathrm{~T}+\frac{\sigma_{\mathrm{S}}^{2} \mathrm{~T}}{2}\right\}\left\{\mathrm{N}\left(\mathrm{d}_{1}\right)\right\}-X \cdot\left\{\mathrm{N}\left(\mathrm{d}_{2}\right)\right\} .\right.
\end{gathered}
$$

where $d_{1}=\frac{\ln \left(\frac{S}{\Delta}\right)+\left(\mu_{s}+\sigma_{S}^{2}\right) \mathrm{T}}{\sigma_{\mathrm{S}} \sqrt{\mathrm{T}}}$ and $d_{2}=\mathrm{d}_{1}-\sigma_{S} \sqrt{T}$. (Note 14)

Equation (5c) shows the expected payoff for a stock option based only on a threshold in stock price and an exercise price (not larger than the threshold).

In his review of option pricing, Smith (1976) notes that Boness (1964) and Samuelson (1965) both consider the valuation of options in terms of a discounted present value of the expected payoff. Equality with Black-Scholes is achieved if $\mu_{S}+\frac{\sigma_{S}^{2}}{2}$ equals the risk-free rate of interest and the risk-free rate is used to discount both the expected future stock price and the exercise price back to the present. Notice, however, that simply discounting expected payoffs without tying the growth rate of the stock price to the risk-free rate is not equivalent to Black-Scholes because $\mathrm{d}_{1}$ in $(5 \mathrm{c})$ also contains $\mu_{S}+\frac{\sigma_{S}^{2}}{2}$. Thus the entire approach of discounting expected future cash flows at risk-adjusted rates is open to criticism as inconsistent with the assumption of continuous dynamic hedging. To side-step this issue, we adopt the terminology of approximate present value to mean the replacement in the expected payoff equations of the expected growth rate of stock price, $\mu_{S}+\frac{\sigma_{S}^{2}}{2}$, by the risk-free rate along with discounting at this rate. In other words, this assumes that both stock price risk and earnings risk can be hedged in order to obtain a risk-neutral valuation. If earnings risk cannot be hedged, then valuation requires adjusting the discount rate to reflect whatever additional risk cannot be hedged; an issue we do not address in the current paper. Throughout our examples we show both the expected contract payoff and its approximate present value.

For the special case of $\mathrm{H}=0$, of course, the approximate present value yields the Black-Scholes option pricing model which, in our notation, is

$$
V_{B S}=S \cdot N\left(d_{1}\right)-e^{-f T} \cdot X \cdot N\left(d_{2}\right)
$$

where $d_{1}=\frac{\ln \frac{S}{\Delta}+f T+\frac{\sigma_{S}^{2} T}{2}}{\sigma_{S} \sqrt{(T)}}, d_{2}=d_{1}-\sigma_{S} \sqrt{T} \quad$, and $f$ is the risk free rate.

In the general case of (4), the approximate present value of the contract would be

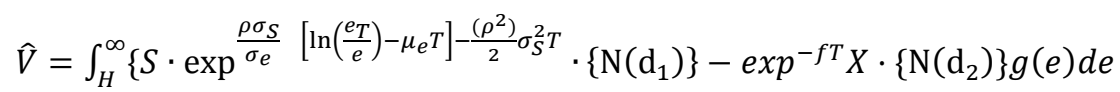

where $d_{1}=\frac{\ln \left(\frac{S}{\Delta}\right)+\frac{\rho \sigma_{S}}{\sigma_{e}}\left[\ln \left(\frac{e_{T}}{e}\right)-\mu_{e} T\right]+f T-\frac{\left(\rho^{2}\right)}{2} \sigma_{S}^{2} T}{\sigma_{\varepsilon} \sqrt{T}}$, and $d_{2}=d_{1}-\sigma_{\varepsilon} \sqrt{T}$.

\subsection{The Limiting Situation Where $X$ and $\triangle$ Are Zero}

One of the most common $\mathrm{p}-\mathrm{v}$ awards has the vesting of a stock grant based on a single accounting criterion. In our framework, these awards set $\mathrm{X}$ and $\Delta$ to zero. Working with (4a), and tracing carefully through the projection of stock price on earnings, the expected payoff for this special case simplifies to

$$
\begin{gathered}
\bar{P}=\int_{H}^{\infty} E\left(S_{T} \mid e_{T}\right) \cdot g(e) d e \\
\bar{P}=E\left(S_{T}\right)\left\{\mathrm{N}\left(\mathrm{d}_{1}\right)\right\} \\
\bar{P}=S \cdot \exp ^{\mu_{S} T+\frac{\sigma_{S}^{2} T}{2}}\left\{\mathrm{~N}\left(\mathrm{~d}_{1}\right)\right\}
\end{gathered}
$$

where $d_{1}=\frac{\ln \left(\frac{\mathrm{e}}{\mathrm{H}}\right)+\mu_{e T}+\rho \sigma_{S} \sigma_{e} T}{\sigma_{e} \sqrt{T}}$.

These results follow from Theorems 1 and 2 in Appendix A

A nice touchstone for $(6 \mathrm{c})$ is that, when stock price and earnings are uncorrelated, the expected payoff reduces to the expected future stock price times the probability that earnings will exceed its threshold. The approximate present value of this type of award is 


$$
\widehat{V}=S \cdot\left\{\mathrm{N}\left(\mathrm{d}_{1}\right)\right\}
$$

where $d_{1}$ is the same as in (6).

Thus, for stock awards that vest solely on achieving an earnings threshold, conversion from the expected payoff to the approximate present value is achieved through multiplication by the ratio of current stock price to the expected future stock price. The haircut in expected payoff created through $\mathrm{N}\left(\mathrm{d}_{1}\right)$ is tied to the mean and variance of the earnings process, the correlation between earnings and stock price as well as the variance of the stock price process. (Note 15)

\subsection{The Extension to Partial Vesting of A Stock Grant over A Range of Performance}

Many a-c awards vary the number of shares granted as earnings moves between a lower threshold and an upper threshold, above which the number is capped. The example of Coca-Cola Enterprises Inc. introduced in section 2.1 illustrates.

As background, Appendix A6, shows the case of a simple stock grant with proportional vesting over a range of outcomes for $\mathrm{S}_{\mathrm{T}}$. Extending to vesting over a range of earnings, let

$$
\begin{gathered}
b\left(e_{T}\right)=0 \text { if } e_{T}<L \\
b\left(e_{T}\right)=\frac{e_{T}-L}{U-L} \text { if } L<e_{T}<U \\
b\left(e_{T}\right)=1 \text { if } U<e_{T} .
\end{gathered}
$$

Following the logic for the case of a simple stock grant, the expected payoff is,

$$
\begin{gathered}
\bar{P}=\int_{U}^{\infty} E\left(S_{T} \mid e_{T}\right) \cdot g(e) d e+\int_{L}^{U} E\left[\frac{e_{T}-L}{U-L}\left(S_{T}\right) \mid e_{T} \cdot g(e) d e\right. \\
\bar{P}=\left[E\left(S_{T} \mid e_{T}>\Delta\right)\right] \operatorname{prob}\left(e_{T}>U\right)+E\left[\frac{e_{T-L}}{U-L}\left(S_{T}\right) \mid L<e_{T}<U\right] \operatorname{prob}\left(L<e_{T}<U\right) \\
\bar{P}=\mathrm{S} \cdot \exp ^{\mu_{S}+\frac{\sigma_{S}^{2} \mathrm{~T}}{2}}\left\{\mathrm{~N}\left(\mathrm{~d}_{\mathrm{U}}\right)\right\}+\frac{e \cdot S}{U-L} \cdot \exp ^{\mu_{S}+\frac{\sigma_{S}^{2} T}{2}}\left\{N\left(d_{L}\right)-N\left(d_{U}\right)\right\} \\
-\frac{L \cdot S}{U-L} \cdot \exp ^{\mu_{e}+\mu_{S}+\frac{\sigma_{e}^{2}+\sigma_{S}^{2} T+2 \rho \sigma_{S} \sigma_{e}}{2}}\left\{N\left(d_{L}^{*}\right)-N\left(d_{U}^{*}\right)\right\}
\end{gathered}
$$

where

$$
\begin{gathered}
d_{L}=\frac{\ln \left(\frac{e}{L}\right)+\left(\mu_{e}+\rho \sigma_{S} \sigma_{e}\right) T}{\sigma_{e} \sqrt{T}} \\
d_{U}=\frac{\ln \left(\frac{e}{U}\right)+\left(\mu_{e}+\rho \sigma_{S} \sigma_{e}\right) T}{\sigma_{e} \sqrt{T}} \\
d_{L}^{*}=\frac{\ln \left(\frac{e}{L}\right)+\left(\mu_{e}+\left(1+\rho \frac{\sigma_{S}}{\sigma_{e}}\right) \sigma_{e}^{2}\right) T}{\sigma_{e} \sqrt{T}} \\
d_{U}^{*}=\frac{\ln \left(\frac{e}{U}\right)+\left(\mu_{e}+\left(1+\rho \frac{\sigma_{S}}{\sigma_{e}}\right) \sigma_{e}^{2}\right) T}{\sigma_{e} \sqrt{T}}
\end{gathered}
$$

The approximate valuation for this case becomes

$$
\begin{gathered}
\widehat{V}=\mathrm{S}\left\{\mathrm{N}\left(\mathrm{d}_{\mathrm{U}}\right)\right\}+\frac{e \cdot S}{U-L}\left\{N\left(d_{L}\right)-N\left(d_{U}\right)\right\} \\
-\frac{L \cdot S}{U-L} \cdot \exp ^{\mu_{e}+\frac{\sigma_{e}^{2} T+2 \rho \sigma_{S} \sigma_{e} T}{2}}\left\{N\left(d_{L}^{*}\right)-N\left(d_{U}^{*}\right)\right\}
\end{gathered}
$$

where the d's are the same as in $(8 \mathrm{c})$.

\subsection{The Expected Payoff with Two Vesting Criteria}

Having considered the case of an award with both an accounting target and a stock-price target, we now consider an award with two different accounting targets (e.g., EPS and sales growth). The 2007 proxy for Aldrich Corp, motivates.

The expected payoff from a stock grant conditioned on the achievement of two accounting hurdles requires a small modification to equation (4). We need to translate from a vesting criterion based on stock price to a second vesting criterion, other than earnings, which is not linked one-for-one with stock price but is correlated with it and also possibly 
correlated with earnings. Extending equation (1), let the second vesting provision be tied to $\mathrm{r}$ (revenue), which is jointly lognormally distributed with earnings and stock price. Vesting of a stock grant requires $\mathrm{r}_{\mathrm{T}}>R$, and $e_{T}>\mathrm{H}$.

Recognizing two performance thresholds in (1) and the fact that the award is a stock grant rather than an option,

$$
\bar{P}=\int_{H}^{\infty} \int_{R}^{\infty}(S) f\left(S_{T} \mid r_{T}, e_{T}\right) g(r, e) d r d e
$$

The inner integral is, again, a partial expectation of $\mathrm{S}$ given $e$ and the fact that $\mathrm{r}$ exceeds $\mathrm{R}$,

$$
\bar{P}=\int_{H}^{\infty} E\left(S \mid e, r_{T}>R\right) \cdot \operatorname{Prob}\left(r_{T}>R \mid e\right) g(e \mid r) d e
$$

where $\mathrm{g}(e \mid r)$ is the conditional distribution of $e_{T}$, given $\mathrm{r}_{\mathrm{T}}$ (Note 16).

Adding joint lognormality defines the conditional distributions and partial expectations. Equation (10) can be written in the form of partial expectations as

$$
\bar{P}=\int_{H}^{\infty} E\left(S_{T} \mid e_{T}\right) \cdot N\left(d_{1}\right) g(e) d e
$$

where $E\left(S_{T} \mid e_{T}\right)$ is as defined in (3),

$$
d_{1}=\frac{\ln \left(\frac{r}{R}\right)+\mu_{r} T+\rho_{\varepsilon, r} \sigma_{\varepsilon} \sigma_{r} T}{\sqrt{\sigma_{r} T}}
$$

$r=$ initial level of revenue

$\mu_{\mathrm{r}}=$ the mean of the change in periodic log revenue

$\rho_{\varepsilon, \mathrm{r}}=$ the correlation between the projection error of log stock price on log earnings (defined in (3)) and $\mathrm{r}_{\mathrm{T}}$

$\mathrm{R}=$ the threshold for $\mathrm{r}_{\mathrm{T}}$,

$\mathrm{g}(\mathrm{e})=$ the unconditional density of earnings.

This solution follows from Theorems 1 and 2 in Appendix $A$, with $Y=S_{T} \mid e_{T}$ and $X=r_{T}$.

The approximate present value becomes

$$
\widehat{V}=\int_{H}^{\infty} \exp ^{-f T} E\left(S_{T} \mid e_{T}\right) N\left(d_{1}\right) g(e) d e
$$

where $d_{1}$ is the same as in (11). In applying (11') we also impose the restriction that the unconditional growth in stock price equals the risk-free rate, as in (4).

\subsection{The Expected Payoff for Compound Options Containing An either/or Condition}

Adding an either/or condition, as in Sotheby's contract, extends the case where all conditions must be met simultaneously. To see how this alters the expected payoff, consider a stock option awarded if either the stock price or earnings exceeds its respective threshold. Working from equation (2), there are three ranges to evaluate, giving three pieces to the expected payoff. The first piece is the partial expectation of $\mathrm{S}_{\mathrm{T}}-\mathrm{X}$ when both $\mathrm{e}_{\mathrm{T}}$ and $\mathrm{S}_{\mathrm{T}}$ exceed their thresholds and is identical to equation 2. The second piece is the partial expectation of $\mathrm{S}_{\mathrm{T}}-\mathrm{X}$ when $e_{T}<\mathrm{H}$ and $\mathrm{S}_{\mathrm{T}}>\Delta$. The sum of the first two pieces is the expected payoff from a simple call option with exercise price of $\mathrm{X}$ and threshold of $\Delta$.

The third piece is the partial expectation of $\mathrm{S}_{\mathrm{T}}-\mathrm{X}$ when $e_{T}>\mathrm{H}$ but $\mathrm{X}<\mathrm{S}_{\mathrm{T}}<\Delta$. Clearly, if $\mathrm{X}=\Delta$, this third piece has zero value and the either/or condition adds nothing to a simple call option. However, when $\Delta>\mathrm{X}$ as, for example, in stock grants wherein $X=0$, the third piece adds meaningful value. It amounts to a premium over a simple option, rather than a haircut implied by the a-c option analyzed in 3.1. Thus, extending equation (2) for the situation where $\Delta>\mathrm{X}$, the either/or condition creates an expected payoff equal to

$$
\bar{P}=E(S-X \mid S>\Delta) \operatorname{prob}(S>\Delta)+\int_{H}^{\infty} E(S-X \mid e, X<S<\Delta) \cdot \operatorname{Prob}(X<S<\Delta \mid e) g(e) d e
$$

The application of (12) to the lognormal case results in (5c) plus a somewhat tedious extension of (4). The final form would be:

$$
\begin{gathered}
\bar{P}=\left\{\mathrm{S} \cdot \exp \left(\mu_{s}+\frac{\sigma_{\mathrm{S}}^{2} \mathrm{~T}}{2}\right\}\left\{\mathrm{N}\left(\mathrm{d}_{1}\right)\right\}-X \cdot\left\{\mathrm{N}\left(\mathrm{d}_{2}\right)\right\}\right. \\
+\int_{H}^{\infty} S \cdot \exp ^{\mathrm{Z}_{\mathrm{T}}+\frac{\left(1-\rho^{2}\right)}{2} \sigma_{S}^{2} \mathrm{~T}} \cdot\left\{\mathrm{N}\left(\mathrm{c}_{1}\right)-\mathrm{N}\left(\mathrm{b}_{1}\right\}-X \cdot\left\{\mathrm{N}\left(\mathrm{c}_{2}\right)-N\left(b_{2}\right\} g(e) d e\right.\right.
\end{gathered}
$$

Where

$$
d_{1}=\frac{\ln \left(\frac{\mathrm{S}}{\Delta}\right)+\left(\mu_{S}+\sigma_{\mathrm{S}}^{2}\right) \mathrm{T}}{\sigma_{\mathrm{S}} \sqrt{\mathrm{T}}} d_{2}=\mathrm{d}_{1}-\sigma_{S} \sqrt{T}
$$




$$
\begin{gathered}
c_{1}=\frac{\ln \left(\frac{\mathrm{S}}{\mathrm{X}}\right)+\mathrm{Z}_{\mathrm{T}}+\sigma_{\varepsilon}^{2} T}{\sigma_{\varepsilon} \sqrt{\mathrm{T}}}, c_{2}=\mathrm{c}_{1}-\sigma_{\varepsilon} \sqrt{T}, \\
b_{1}=\frac{\ln \left(\frac{\mathrm{S}}{\Delta}\right)+\mathrm{Z}_{\mathrm{T}}+\sigma_{\varepsilon}^{2} T}{\sigma_{\varepsilon} \sqrt{\mathrm{T}}}, b_{2}=\mathrm{b}_{1}-\sigma_{\varepsilon} \sqrt{T} .
\end{gathered}
$$

For proof of these results see Appendix, A.5.

The approximate present value involves discounting at the risk-free rate in conjunction with the restriction that the unconditional growth rate of stock price equals the risk-free rate.

\subsection{Adding Subjective Valuation}

The expressions for expected payoffs all involve integration over possible stock price and accounting earnings outcomes. It is relatively straightforward to track the variability of the possible payoffs as another statistic, along with expected payoff. A sense for the subjective valuation of an award based on mean-variance utility of a poorly diversified manager is then easily computed. (Note 17) (Note 18)

\subsection{Summary remarks about expected payoffs to a-c awards}

Subsections 3.1 through 3.5 contain the essential building blocks for evaluating a wide range of vesting scenarios seen in practice. It is a matter of piecing together the various elements and selecting appropriate distributional assumptions. (Note 19) That numerical integration is required for all but the simplest awards should not be off putting. The notation $\mathrm{N}\left(\mathrm{d}_{1}\right)$ within a simple Black-Scholes formula indicates an unavoidable integration, just a familiar one. Nevertheless, a calculator to evaluate expected value, approximate present value and subjective valuation of stock awards containing thresholds in stock price and earnings (3.1) is available from the authors.

\section{Examining Incentive Properties}

The addition of some structure to the relation between earnings and stock price will be helpful in the interpretation of comparative statics. Without structure, it is not clear what it means to change earnings volatility, say, while holding stock-price volatility constant. Since stock price and earnings are structurally related what does it mean to increase earnings without increasing stock price? How can independent variation in stock price and earnings be modeled? To create a bivariate process for earnings and stock price that allows for interpretation of comparative statics, we set up the process as follows.

Assume stock price, $\mathrm{S}_{\mathrm{T}}$, is homothetic in a conceptual valuation driver, $e_{T}^{*}$, called "economic earnings." Future economic earnings are lognormally distributed. Let the reported earnings, $e_{\mathrm{T}}$, on which performance vesting is determined, be economic earnings times a lognormally distributed multiplicative error term, uncorrelated with $e_{T}^{*}$ having mean of unity. We consider first the case where the multiplier linking stock price to economic earnings is an intertemporal constant, and then the case where the multiplier contains a multiplicative lognormal random component that varies over time. The goal is to understand when and how a-c awards help align the interests of managers and shareholders.

\subsection{The Multiplier Is An Intertemporal Constant}

In an environment where $\mathrm{M}$ is an intertemporal constant, we can write

$$
S_{T}=M \cdot e_{T}^{*}, \ln S_{T}=\ln M+\ln e_{T}^{*}
$$

and

$$
e_{T}=e_{T}^{*} \cdot v_{T}, \ln e_{T}=\ln e_{T}^{*}+\ln v_{T}
$$

where $\mathrm{M}$ is the multiplier linking stock price to economic earnings and $v_{T}$ is the error in reported earnings having $\mathrm{E}\left(v_{T}\right)=1$ and $\mathrm{E}\left(\ln v_{T}\right)=-\frac{\left(1-\rho^{2}\right) \sigma_{S}^{2}}{2 \rho^{2}}$ Applied to (3), this structure implies $\sigma_{e}^{2}=\frac{\sigma_{S}^{2}}{\rho^{2}}$ and $\mu_{e}=\mu_{S}-\frac{\left(1-\rho^{2}\right) \sigma_{S}^{2}}{2 \rho^{2}}$,which simplifies the expressions for the expected payoffs considerably. In addition, the approximate present value expressions are greatly simplified if it is assumed that the performance vesting metric is itself a traded asset. If $e_{T}$ has the dynamics of the stock price of another firm or a fixed multiple of such a stock price, then equation (4') reduces to:

$$
\widehat{V}=\int_{H}^{\infty}\left(S \cdot \exp ^{\rho^{2}\left[\ln \left(\frac{e_{T}}{e}\right)-f T\right]+\frac{\sigma_{\varepsilon}^{2}}{2} T} \cdot\left\{\mathrm{N}\left(\mathrm{d}_{1}\right)\right\}-\exp ^{-f T} X \cdot\left\{\mathrm{N}\left(\mathrm{d}_{2}\right)\right\}\right) g(e) d e
$$

with $d_{1}=\frac{\ln \left(\frac{S}{\Delta}\right)+\rho^{2} \ln \left(\frac{e_{T}}{e}\right)+\left(1-\rho^{2}\right) f T-\frac{\sigma_{\varepsilon}^{2}}{2} T}{\sigma_{\varepsilon}^{2} \sqrt{T}}$, and $d_{2}=\mathrm{d}_{1}-\sigma_{\varepsilon} \sqrt{T}$.

Equation (6'), where there is no stock threshold and the award is a stock grant, reduces to 


$$
\widehat{V}=S \cdot\left\{\mathrm{N}\left(\mathrm{d}_{1}\right)\right\}
$$

where $d_{1}=\frac{\ln \left(\frac{e}{H}\right)+f T+\frac{\sigma_{e}^{2}}{2} T}{\sigma_{e} \sqrt{T}}$. (17) is interesting in that it appears as though the correlation between earnings and stock price does not affect the approximate present value. This is deceptive because the correlation affects $\sigma_{e}$ through $\sigma_{e}^{2}=\frac{\sigma_{S}^{2}}{\rho^{2}}$ in this model.

\subsection{The Multiplier Is Time-varying}

With a fixed multiplier, there is little reason for a compensation committee and the manager to jointly prefer a-c contracts over contracts having payoffs tied exclusively to stock price. This is because creating incentives for managers to focus on earnings essentially gives them incentives to create positive error in reported earnings. These errors do not necessarily enhance the value of the firm because the market should be able to see through them. A traditional option would be a superior tool because it shifts the manager's attention away from manipulating earnings around fundamental earnings.

The stock price/earnings dynamics shown in (14) and (15) can be enriched to include variation in $M$ that is outside the control of managers (e.g. caused by exogenous changes in discount rates). Where variation in $M$ is exogenous to manager effort, a-c awards can tie manager payoffs more closely to something within his or her control. This creates a tension between incentivizing managers to focus on the error component in reported earnings and reducing the volatility in manager compensation caused by forces outside management control. (Note 20) In this subsection we flesh out a structure that allows these forces to influence the choice of $\mathrm{p}-\mathrm{v}$ awards and their impact on manager effort and effectiveness.

Assume that the multiplier at time $\mathrm{T}, \mathrm{M}_{\mathrm{T}}=\mathrm{M} \cdot \mathrm{m}_{\mathrm{T}}$ where $\mathrm{m}_{\mathrm{T}}$ is a lognormal trend in the multiplier with $\mathrm{E}\left(\mathrm{m}_{\mathrm{T}}\right)=\mathrm{G}$

$$
m_{T} \sim L N\left(\exp (G)-.5 \sigma_{m}^{2}, \sigma_{m}^{2}\right)
$$

Let $\theta=$ the portion of stock volatility caused by true earnings volatility and

$\Gamma=$ the portion of earnings volatility caused by true earnings volatility.

The correlation between log stock price and reported earnings would then be (Note 21)

$$
\rho=[\theta \Gamma]^{1 / 2}
$$

Within this structure,

$$
S_{T}=M_{T} \cdot e_{T}^{*}, \ln S_{T}=\ln M+\ln m_{T}+\ln e_{T}^{*}
$$

and

$$
e_{T}=e_{T}^{*} \cdot v_{T}, \ln e_{T}=\ln e_{T}^{*}+\ln v_{T}
$$

$v_{T}$, the error in reported earnings has $\mathrm{E}\left(v_{T}\right)=1$ and $\mathrm{E}\left(\ln v_{T}\right)=-\frac{\theta(1-\Gamma) \sigma_{S}^{2}}{2 \Gamma}$. Applied to (3), this structure implies $\sigma_{m}^{2}=(1-\theta) \sigma_{S}^{2}, \sigma_{e}^{2}=\frac{\theta \sigma_{S}^{2}}{\Gamma}$ and $\mu_{e}=\mu_{S}-\ln G+.5(1-\theta) \sigma_{S}^{2}+\frac{\theta(1-\Gamma) \sigma_{S}^{2}}{2 \Gamma}$.

Application of the model requires the inputs $\sigma_{s}^{2}, \rho$ or $\Gamma, \mu_{S}, \mathrm{G}$ and $\theta$. These parameters allow calculation of expected payoff and approximate present value in a straightforward manner because they also drive the volatility and mean of earnings.

\section{Comparative Statics}

The structure in Section 4.2 allows for meaningful comparative statics contrasting traditional options with a-c awards. In this section we focus on awards having stock grants as the back-end instrument. The goal is to clarify how imposing a hurdle in earnings contrasts with imposing a hurdle in stock price when awarding incentive compensation.

We first describe some intuition in the context of the parameters set forth in section 4.2. As $\Gamma$ increases across otherwise identical firms, the distraction of manipulating the error in earnings diminishes in that efforts directed toward increasing earnings are directed more squarely on economic earnings as gamma increases. As $\theta$ increases, the impact of random changes in the multiplier has an increasingly greater influence on the value of both back-end instruments. But this effect is greater for traditional options because it affects the likelihood of achieving a stock price threshold. Awards vested on the basis of earnings reduce the influence of randomness in the multiplier in that this multiplier does not affect the likelihood of achieving an earnings threshold. 
Examining how stock-price volatility affects expected payoffs and present value is complicated by the fact that stock volatility represents a combination of multiplier volatility and economic earnings volatility. One interesting comparison is to hold stock volatility constant and change the proportion, $\theta$, of volatility driven by earnings. As $\theta$ increases, the influence of earnings increases and alters both the expected payoff and approximate present value of $\mathrm{p}-\mathrm{v}$ awards containing an earnings hurdle. Changing $\theta$ has no effect on traditional stock options.

Tracing the influence of shocks to stock prices or earnings, a pure earnings increase with no parallel increase in stock price would represent the influence of a change in earnings measurement error. A pure increase in stock price with no parallel increase in earnings is captured by a change in the multiplier. These two effects reflect an important element of the tension created with a-c awards. Changes in the multiplier, $\mathrm{M}_{\mathrm{T}}$, affect the value of both traditional options and a-c awards but the impact on a-c awards is lessened because a change in multiplier does not affect the likelihood of reaching the earnings hurdle. In contrast, a change in earnings not accompanied by a change in stock price is the result of a change in earnings measurement error. The latter change does not impact valuation for traditional stock options but it affects the likelihood of vesting in a-c awards, and thus their expected payoff and valuation.

The comparative statics reveal tradeoffs faced by firms considering a-c awards as alternatives to traditional stock options. Firms more subject to earnings manipulation (high $\Gamma$ ) should tend to favor stock options. Firms whose managers can more easily or greatly impact economic earnings should favor a-c awards. Firms more subject to changes in earnings multipliers outside management control should favor a-c awards. The level of stock volatility should not be a major driver in the choice. What matters is the relative contribution of multiplier, economic earnings and deviations in reported earnings along with the capacity of managers to influence these value drivers.

\section{Conclusion and Potential for Future Research}

We present a structure to examine the expected payoff from equity compensation under accounting contingencies. The exercise is relevant to a range of constituents including academics, board members, shareholders and regulators. The model incorporates observed characteristics of these awards; multiple performance targets, sliding payout schedules, either/or conditions, and the existence of at least one vesting condition based on accounting performance. At this juncture, it is doubtful that compensation committees understand the payout distributions of a-c awards well enough to grant awards optimally. Yet a-c awards are commonly granted, and academics are eager to understand what types of firms utilize them and why.

Research into how accounting contingencies influence equity compensation is still preliminary, with significant room for additional work. In particular, an important next step is to attempt empirical estimation of the expected payoffs and approximate present value for samples of contracts actually granted by firms. This step will address a host of questions concerning the measurement of the input parameters and the viability of the joint lognormal distribution assumption.

Once there is comfort with valuing a-c awards, it should be possible to better address what kinds of firms should favor these awards and how firms should set award parameters. Not until then can we understand how a-c awards are fundamentally different (if at all) from equity plus cash bonus tied to accounting targets. The hope is that this paper provides a foundation from which to build going forward. One immediate insight is that folding all of the forces at work into an optimal contracting framework will result in a word of caution about interpreting correlations between the existence of a-c awards and subsequent earnings manipulation. While a sample of firms drawn at random and injected with a-c awards might see increased earnings manipulation, firms most susceptible to manipulation should be less likely to offer these types of awards. In the cross-section, it isn't possible to say immediately whether firms that choose a-c awards will have more manipulation than those that don't.

One important future direction is to structure the use of relative-performance vesting wherein vesting is based on exceeding the earnings growth of competing firms rather than a fixed target. Our framework is well-suited to this extension.

\section{References}

Antle, R., \& A. Smith. (1986). An Empirical Investigation of the Relative Performance Evaluation of Corporate Executives. Journal of Accounting Research, 24, 1-39. http://dx.doi.org/10.2307/2490802

Armstrong, C. \& R. Vashishtha. (2012). Executive Stock Options, Differential Risk-Taking Incentives and Firm Value. Journal of Financial Economics, 104, 70-88. http://dx.doi.org/10.1016/j.jfineco.2011.11.005

Beatty, R., S. Riffe, \& R. Thomson. (2000). IPO Pricing with Accounting Information, working paper, Southern Methodist University. 
Bettis, C., J. Bizjak, J. Coles, \& S. Kalpathy. (2015). Performance-Vesting Provisions in Executive Compensation, working paper, Arizona State University.

Bizjak, J. R. Hayes, \& S. Kalpathy. (2015). Performance-Contingent Executive Compensation and Managerial Behavior, TCU working paper.

Black, F., \& M. Scholes. (1973). The Pricing of Options and Corporate Liabilities. Journal of Political Economy, 81, 637-654. http://dx.doi.org/10.1086/260062

Boness, A.J. (1964). Elements of a Theory of Stock-Option value. Journal of Political Economy, 72, 163-175. http://dx.doi.org/10.1086/258885

Clinch, G., \& J. Magliolo. (1993). CEO Compensation and Components of Earnings in Bank Holding Companies. Journal of Accounting and Economics, 16, 241-272. http://dx.doi.org/10.1016/0165-4101(93)90013-6

Core, J., Guay, W., \& D. Larcker. (2003). Executive Equity Compensation and Incentives: A Survey. Economic Policy Review, 9, 27-50.

Ely, K. (1991). Inter-industry Differences in the Relation between Compensation and Firm Performance Variables. Journal of Accounting Research, 29, 37-58. http://dx.doi.org/10.2307/2491027

Finn, M., \& J. Ye. (1999). Nonlinear Accounting-Based Equity Valuation Models, working paper, Northwestern University.

Frydman, C., D. Jenter. (2010). CEO Compensation, working paper, Stanford University.

Hand, J.M. (2000). Profits, Losses and the Non-Linear Pricing of Internet Stocks, working paper, University of North Carolina at Chapel Hill.

Holden, C. \& D. Kim. (2014). Performance Share Plans: Valuation, Optimal design, and Empirical Tests, working paper, Indiana University.

ISS. (2016). Benchmark Policy Updates, Institutional Shareholder Services, issgovernance.com

Jensen, M., \& K. Murphy. (1990). Performance Pay and Top-Management Incentives. Journal of Political Economy, 98, 225-264. http://dx.doi.org/10.1086/261677

Johnson, S., \& Y. Tian. (2000A). The Value and Incentive Effects of Nontraditional Executive Stock Option Grants. Journal of Financial Economics, 57, 3-34. http://dx.doi.org/10.1016/S0304-405X(00)00049-0

Johnson, S., \& Y. Tian. (2000B). Indexed Executive Stock Options, Journal of Financial Economics, 57, 35-64. http://dx.doi.org/10.1016/S0304-405X(00)00050-7

Kim, D., Yang, J. (2014). Beating The Target: Performance Management Around the Annual Incentive Target, working paper, Indiana University

Kuang, Y., J. Suijs. (2006). Incentive Effects of Performance-Vested Stock Options, working paper, Tilburg University.

Kuang, Y., \& B. Quin. (2009). Performance-Vested Stock Options and Interest Alignment. British Accounting Review, 41, 46-61. http://dx.doi.org/10.1016/j.bar.2008.10.001

Lambert, R. A., \& D. F. Larcker. (1987). An Analysis of the Use of Accounting and Market Measures of Performance in Executive Compensation Contracts. Journal of Accounting Research, 25, 85-129. http://dx.doi.org/10.2307/2491081

Murphy, K. (1999). Executive compensation. In: Ashenfelter, O., Card, D. (Eds.), Handbook of Labor Economics, Vol. 3. North-Holland, Amsterdam. http://dx.doi.org/10.2139/ssrn.163914

Murphy, K. J. (2013). Executive Compensation: Where we are, and How we Got There, in Constantinides, G., Harris, M., and Stulz, R., eds., Handbook of the Economics of Finance, Elsevier Science North Holland, Elsevier. http://dx.doi.org/10.1016/b978-0-44-453594-8.00004-5

Park, H \& D. Vrettos. (2015). The Moderating Effect of Relative Performance Evaluation on the Risk Incentive Properties of Executives' Equity Portfolios. Journal of Accounting Research, 53, 1055-1108. http://dx.doi.org/10.1111/1475-679X.12092

PricewaterhouseCoopers. (2011). Global Equity Incentives Survey: The Rise of Performance-based Equity. 
Riffe, S. \& R. Thompson. (1997). The Relation Between Stock Prices and Accounting Information. Review of Accounting Studies, 2, 325-351. http://dx.doi.org/10.1023/A:1018663519739

Samuelson, P.A. (1965). Rational Theory of Warrant Pricing. Industrial Management Review, 6, 13-31.

Sloan. R. G. (1993). Accounting Earnings and Top Executive Compensation. Journal of Accounting and Economics, 16, 55-100. http://dx.doi.org/10.1016/0165-4101(93)90005-Z

Smith, C.W. (1976). Option Pricing, a Review. Journal of Financial Economics, 3, 3-51. http://dx.doi.org/10.1016/0304-405X(76)90019-2

Tian, Y. (2004). Too Much of a Good Incentive? The case of executive stock options. Journal of Banking and Finance, 28, 1225-1254. http://dx.doi.org/10.1016/S0378-4266(03)00122-5

\section{Appendix A. Partial expectations under the lognormal distribution.}

Some of the partial expectations used in Section 3 are generalizations of the univariate formulas for partial expectation because they involve the partial expectation of one random variable conditioned on the level of another, related variable. For the lognormal distribution, this appendix supplies the univariate partial expectation and two theorems helpful in extending to the multivariate case.

\section{Univariate partial expectation relations and Black-Scholes valuation}

The partial expectation of a random variable $X$ with respect to a threshold $k$ is defined as $g(k)=\mathrm{E}[X \mid X>k] \mathrm{P}[X>k]$. For a log-normal random variable the partial expectation is given by

$$
g(k)=\int_{k}^{\infty} x f(x) d x=e^{\mu+\frac{1}{2} \sigma^{2}} \Phi\left(\frac{\mu+\sigma^{2}-\ln k}{\sigma}\right)
$$

2. Theorem 1: Let $X$ be a lognormally distributed random variable with $\mathrm{k}$ and $\beta$ positive constants. $E\left(X^{\beta} \mid X>k\right) \operatorname{Prob}(X>k)=E\left(X^{\beta}\right) N\left(d_{1}\right)$ where $d_{1}=\frac{\mu_{X}+\beta \sigma_{X}^{2}-\ln (k)}{\sigma_{X}}$.

Proof: First recognize that $\operatorname{prob}(X>k)=\operatorname{prob}\left(X^{\beta}>k^{\beta}\right)$.

It follows that $E\left(X^{\beta} \mid X>k\right)=E\left(X^{\beta} \mid X^{\beta}>k^{\beta}\right)$.

Next, if $X \sim L N\left(\mu_{X}, \sigma_{X}\right)$, then $X^{\beta} \sim L N\left(\beta \mu_{X}, \beta \sigma_{X}\right)$.

Using the formula for the partial expectation of a truncated lognormal,

$E\left(X^{\beta} \mid X>k\right) \operatorname{Prob}(X>k)=E\left(X^{\beta} \mid X^{\beta}>k^{\beta}\right) \operatorname{prob}\left(X^{\beta}>\mathrm{k}^{\beta}\right)=E\left(X^{\beta}\right) N\left(d_{1}\right)$

where $d_{1}=\frac{\beta \mu_{X}+\beta^{2} \sigma_{X}^{2}-\beta \ln (k)}{\beta \sigma_{X}}=\frac{\mu_{X}+\beta \sigma_{X}^{2}-\ln (k)}{\sigma_{X}}$ QED.

3. Theorem 2: Let $x$ and y be two jointly lognormally distributed random variables with

$X$
$Y$ $\operatorname{MLN}\left\{\begin{array}{l}\mu_{X} \\ \mu_{Y}\end{array}, T \cdot\left[\begin{array}{cc}\sigma_{X}^{2} & \rho \sigma_{X} \sigma_{Y} \\ \rho \sigma_{X} \sigma_{Y} & \sigma_{Y}^{2}\end{array}\right]\right\}$

and define the projection equation

$\ln Y=\mu_{Y}+\beta \cdot\left(\ln X-\mu_{X}\right)+\varepsilon$

$\ln Y=Z+\varepsilon$

and

$\beta=\rho \sigma_{Y} / \sigma_{X}$.

Then $\int_{K}^{\infty} E(Y \mid X) \cdot g(X) d X=E(Y \mid X>K) \operatorname{prob}(X>K)=E(Y) N(d 1)$

where $d_{1}=\frac{\mu_{X}+\rho \sigma_{Y} \sigma_{X}-\ln (K)}{\sigma_{X}}$.

Proof:

$\int_{K}^{\infty} E(Y \mid X) \cdot g(X) d X=\int_{K}^{\infty} \exp ^{\mathrm{Z}+\frac{\left(1-\rho^{2}\right)}{2} \sigma_{\mathrm{Y}}^{2}} g(X) d X$

$=\int_{K}^{\infty} \exp ^{\mu_{\mathrm{Y}}+\frac{1}{2} \sigma_{\mathrm{Y}}^{2}+\beta\left(\mathrm{X}-\mu_{\mathrm{X}}\right)-\frac{\rho^{2}}{2} \sigma_{\mathrm{Y}}^{2}} g(X) d X$ 
$=\int_{K}^{\infty} E(Y) \exp ^{\beta\left(X-\mu_{X}\right)-\frac{\beta^{2}}{2} \sigma_{X}^{2}} g(X) d X$

$=\int_{K}^{\infty} E(Y) E^{-1}\left(X^{\beta}\right) X^{\beta} g(X) d X$.

Applying theorem 1 yields

$\int_{K}^{\infty} E(Y) E^{-1}\left(X^{\beta}\right) X^{\beta} g(X) d X=E(Y) E^{-1}\left(X^{\beta}\right) E\left(X^{\beta}\right) N\left(d_{1}\right)$

where $d_{1}=\frac{\beta \mu_{X}+\beta^{2} \sigma_{X}^{2}-\beta \ln (k)}{\beta \sigma_{X}}=\frac{\mu_{X}+\beta \sigma_{X}^{2}-\ln (k)}{\sigma_{X}}=\frac{\mu_{X}+\rho \sigma_{Y} \sigma_{X}-\ln (k)}{\sigma_{X}}$. QED (Note 22)

\section{Proof of $(6 b)$ :}

$\bar{P}=\int_{H}^{\infty} E\left(S_{T}-X \mid e_{T}, S_{T}>\Delta\right) \cdot \operatorname{Prob}\left(S_{T}>\Delta \mid e_{T}\right) g(e) d e$

$=\int_{H}^{\infty} E\left(S_{T} \mid e_{T}\right) \cdot g(e) d e$

Using Theorems 1 and 2 above and the notation in the text,

$\bar{P}=E\left(S_{T}\right)\left\{\mathrm{N}\left(\mathrm{d}_{1}\right)\right\}$

where $d_{1}=\frac{\ln \frac{e}{H}+\mu_{e} T+\rho \sigma_{S} \sigma_{e} T}{\sigma_{e} \sqrt{T}}$.

5. Proof of Equation (13). The partial expectation inside the integral of (12) is two sided. A two sided partial expectation has partial expectation equal to the partial expectation above the lower limit, in this case $\mathrm{X}$, minus the partial expectation above the upper limit, in this case $\Delta$. Thus

$$
\begin{gathered}
E(S-X \mid e, X<S<\Delta) \cdot \operatorname{Prob}(X<S<\Delta \mid e) \\
=E(S \mid e)\left\{\mathrm{N}\left(\mathrm{c}_{1}\right)-\mathrm{N}\left(\mathrm{b}_{1}\right)\right\}-X \cdot\left\{\mathrm{N}\left(\mathrm{c}_{2}\right)-N\left(b_{2}\right)\right\} . \\
c_{1}=\frac{\ln \left(\frac{\mathrm{S}}{\mathrm{x}}\right)+\mathrm{z}_{\mathrm{T}}+\sigma_{\varepsilon}^{2} T}{\sigma_{\varepsilon} \sqrt{\mathrm{T}}}, c_{2}=\mathrm{c}_{1}-\sigma_{\varepsilon} \sqrt{T} \\
b_{1}=\frac{\ln \left(\frac{\mathrm{S}}{\Delta}\right)+\mathrm{z}_{\mathrm{T}}+\sigma_{\varepsilon}^{2} T}{\sigma_{\varepsilon} \sqrt{\mathrm{T}}}, b_{2}=\mathrm{b}_{1}-\sigma_{\varepsilon} \sqrt{T}
\end{gathered}
$$

The rest of equation (13) follows easily.

\section{Proportional vesting over a range of outcomes for the performance metric.}

To address this particular feature of $\mathrm{p}-\mathrm{v}$ awards, consider first a simple stock grant that pays $\mathrm{b}\left(\mathrm{S}_{\mathrm{T}}\right)$ according to the process:

$b\left(S_{T}\right)=0$ if $S_{T}<L$

$b\left(S_{T}\right)=\frac{S_{T}-L}{U-L}$ if $L<S_{T}<U$

$b\left(S_{T}\right)=1$ if $U<S_{T}$

Using theorem 1 above in moving from (A9) to the third term in (A10), it is straightforward to show that

$\bar{P}=\int_{U}^{\infty}\left(S_{T}\right) \cdot f(S) d S+\int_{L}^{U} \frac{S_{T}-L}{U-L}\left(S_{T}\right) \cdot f(S) d S$

$\bar{P}=\left[E\left(S_{T} \mid S_{T}>\Delta\right)-X\right] \operatorname{prob}\left(S_{T}>\Delta\right)+E\left[\frac{U-S_{T}}{U-L}\left(S_{T}\right) \mid L<S_{T}<U\right] \operatorname{prob}\left(L<S_{T}<U\right)$

$\bar{P}=\mathrm{S} \cdot \exp ^{\mu_{S} \mathrm{~T}+\frac{\sigma_{\mathrm{S}}^{2} \mathrm{~T}}{2}}\left\{\mathrm{~N}\left(\mathrm{~d}_{\mathrm{U}}\right)\right\}$

$+\frac{\mathrm{S}^{2}}{\mathrm{U}-\mathrm{L}} \cdot \exp ^{\mu_{S} \mathrm{~T}+\frac{\sigma_{\mathrm{S}}^{2} \mathrm{~T}}{2}}\left\{\mathrm{~N}\left(\mathrm{~d}_{\mathrm{L}}\right)-\mathrm{N}\left(\mathrm{d}_{\mathrm{U}}\right)\right\}$

$-\frac{L S}{\mathrm{U}-\mathrm{L}} \cdot \exp ^{2 \mu_{S} \mathrm{~T}+\frac{4 \sigma_{\mathrm{S}}^{2} \mathrm{~T}}{2}}\left\{\mathrm{~N}\left(\mathrm{~d}_{\mathrm{L}}^{*}\right)-\mathrm{N}\left(\mathrm{d}_{\mathrm{U}}^{*}\right)\right\}$

where

$$
\begin{gathered}
d_{L}=\frac{\ln \left(\frac{S}{\mathrm{~L}}\right)+\left(\mu_{S}+\sigma_{\mathrm{S}}^{2}\right) \mathrm{T}}{\sigma_{\mathrm{S}} \sqrt{\mathrm{T}}} \\
d_{U}=\frac{\ln \left(\frac{\mathrm{S}}{\mathrm{U}}\right)+\left(\mu_{S}+\sigma_{S}^{2}\right) \mathrm{T}}{\sigma_{\mathrm{S}} \sqrt{\mathrm{T}}}
\end{gathered}
$$


$d_{L}^{*}=\frac{\ln \left(\frac{S}{\mathrm{~L}}\right)+\left(\mu_{S}+2 \sigma_{S}^{2}\right) \mathrm{T}}{\sigma_{S} \sqrt{T}}$

$d_{U}^{*}=\frac{\ln \left(\frac{\mathrm{S}}{\mathrm{U}}\right)+\left(\mu_{S}+2 \sigma_{S}^{2}\right) \mathrm{T}}{\sigma_{S} \sqrt{\mathrm{T}}}$

Approximate present value, which would be equivalent to Black-Scholes in this case, requires setting the expected growth rate of the stock and discount rate equal to $f$ in computing the present value of (A11). Thus

$\hat{V}=\mathrm{S}\left\{\mathrm{N}\left(\mathrm{d}_{\mathrm{U}}\right)\right\}+\frac{S^{2}}{U-L}\left\{N\left(d_{L}\right)-N\left(d_{U}\right)\right\}$

$-\frac{L S}{U-L} \cdot \exp ^{f T+2 \sigma_{S}^{2} T}\left\{N\left(d_{L}^{*}\right)-N\left(d_{U}^{*}\right)\right\}$

where

$d_{L}=\frac{\ln \left(\frac{S}{L}\right)+\left(f+\frac{\sigma_{S}^{2}}{2}\right) T}{\sigma_{S} \sqrt{T}}$

$d_{U}=\frac{\ln \left(\frac{S}{U}\right)+\left(f+\frac{\sigma_{S}^{2}}{2}\right) T}{\sigma_{S} \sqrt{T}}$

$d_{L}^{*}=\frac{\ln \left(\frac{S}{L}\right)+\left(f+\frac{3 \sigma_{S}^{2}}{2}\right) T}{\sigma_{S} \sqrt{T}}$

$d_{U}^{*}=\frac{\ln \left(\frac{S}{U}\right)+\left(f+\frac{3 \sigma_{S}^{2}}{2}\right) T}{\sigma_{S} \sqrt{T}}$.

\section{Notes}

Note 1. For more thorough discussion of executive compensation see Murphy (1999), Core, Guay, and Larcker (2003), and Frydman and Jenter (2010).

Note 2. See "Commentary: Paying for Pulse" Forbes.com, October $15^{\text {th }} 2008$.

Note 3. Performance-vesting conditions are also becoming more important in short term and long term cash bonuses. In addition, recently, there has been a push by firms to use what are referred to as performance-based deferrals of annual cash bonuses which convert the annual bonus to shares of common stock once the performance targets are met.

Note 4. PriceWaterhouseCoopers (2011) notes that "a larger percentage of companies also expect to see a shift to compensation contingent on performance for an increased employee population." Further, it appears that the emphasis on performance vesting is not unique to the U.S. Kuang and Quin (2009) find that, in 2004, 244 of the 350 largest UK firms granted stock option awards with performance-vesting conditions. It is natural to conclude that the use of accounting contingencies is also growing internationally and deeper into the employee population.

Note 5. A number of institutions such as CalPERS 2008, TIAA CREF and proxy research services, Institutional Shareholder Services, 2007 have advocated for the adoption of these awards.

Note 6. It is quite common to have multiple vesting conditions in a short term bonus award. Even though most bonus awards are paid in cash there are bonus awards that payout in stock. Consequently, what follows is also a model that could be used to value these types of bonus awards.

Note 7. More specifically, Johnson and Tian (2000A and B) analyze the value and incentive effects of premium options, performance-vested options, repriceable options, purchased options, reload options, and indexed options.

Note 8. An early body of empirical research examines the role played by accounting earnings in managerial compensation. See Antle and Smith (1986), Lambert and Larcker (1987), Jensen and Murphy (1990), Clinch and Magliolo (1993), Ely (1991), and Sloan (1993). None of these studies, however, examine equity awards with accounting contingencies.

Note 9. The necessary assumptions and machinery required to demonstrate an equilibrium relation between features of the contract and the present value of traded securities at an arbitrary time before expiration is deferred to future research. This allows us to shift focus away from continuous time processes for stock price and performance measures and toward assumptions about the distributions of terminal payoffs. While this greatly simplifies the analysis and sidesteps a host of technical issues, it forces us to suggest that a full treatment of the technical issues 
will affect conclusions about valuation and incentives at a second order of importance. Comparisons, shown below, between our approximate valuations and those under Black and Scholes (1973) suggest this to be true.

Note 10. We use "partial expectation" to mean the conditional expectation of a random variable, given that another random variable exceeds a threshold, times the probability that the second random variable exceeds its threshold. This is a slight generalization of the typical use of the term, in which the two random variables are the same.

Note 11. Assuming joint normality for stock price and performance metrics leads to a similar level of complexity in calculating the expected payoffs from a-c awards. Results are not greatly dissimilar to the lognormal case for small $\mathrm{T}$. These results are available from the authors.

Note 12. Empirically, the log-linear model with stock price and untransformed earnings seems to perform well in cross-section as indicated by Hand (2000) for high tech firms and Beatty, Riffe and Thompson (2000) for IPO's. In addition, Finn and Ye (1999) consider several nonlinear models similar to the log-linear model and show that these forms perform well against more traditional linear forms. Interestingly, none of these papers have seen the light of publication. Holden and Kim (2014) make the clever assumption that earnings and the log of stock price are jointly normal, which is to assume that raising exp to the power of earnings creates a lognormally distributed performance metric. One rigorous investigation into the joint distribution of earnings and stock price is Riffe and Thompson (1998), which concludes that the relation between earnings and stock price is likely non-monotonic at the low end of earnings. Note 13 . With this notation, $\mathrm{g}(\mathrm{S} \mid \mathrm{e})$ is the lognormal with mean $\mathrm{Z}_{\mathrm{T}}$ and variance $\sigma_{\varepsilon}^{2}=\left(1-\rho^{2}\right) \sigma_{S}^{2}$.

Note 14. This expression corresponds to equation 22 in Smith (1976).

Note 15. Adding economic structure tying stock price to earnings gives more meaning to $d_{1}$. We discuss a special case in Section 4.

Note 16. This function, although appearing cumbersome is straight forward to program. Adding ranges to the hurdles, where the portion of the grant is tied to $\mathrm{r}$ and $e$ simply requires adding $\mathrm{b}(\mathrm{r}, e)$ to the expression inside the integral in eqn.(10).

Note 17. Application of subjective valuation to stylized a-c awards indicates that it tends to be lower than, say, approximate present value, but directional sensitivity to changes in input parameters is largely retained.

Note 18. More sophisticated approaches to subjective valuation involving hedging of systematic risk and other utility functions can also be implemented. See Tian (2004) and Armstrong and Vashishtha (2012) for application to stock option awards without accounting contingencies.

Note 19. Relative performance awards, which are gaining popularity, can also be handled by simply defining the earnings metric as a suitable transformation of earnings relative to a peer group.

Note 20. A recent empirical investigation by Bizjak, Hayes and Kalpathy (2015) suggests that the use of accounting-based compensation metrics is associated with more earnings management. Kim and Yang (2014) find evidence that there is an empirical connection between performance management and annual incentive targets.

Note 21. $\rho=\frac{\operatorname{Cov}(S, e)}{\sigma_{S} \sigma_{e}}=\frac{\sigma_{e^{*}}^{2}}{\sigma_{S} \sigma_{e}}=\frac{\sigma_{e^{*}}}{\sigma_{S}} \cdot \frac{\sigma_{e^{*}}}{\sigma_{e}}=[\theta \Gamma]^{1 / 2}$

Note 22. We humbly submit that these proofs undoubtedly exist in the statistics literature. Proofs are offered here for completeness. We enjoyed doing them! 